This report was prepared as an accounl of work sponsored by an agency of the United States Government. Neither the United States Government nor any agency thereof, nor any of their employees, makes any warranty, express or implied, or assumes any legal liability or responsibility for the aceuracy, completeness, or usefulness of any information, apparatus, product, or process disclosed. or represents that its use would not infringe privately owned rights. Reference herein to any specific commercial product, process, or service by trade name, trademark, manufacturer, or otherwise does not necessarily constiatule or imply its endorsement, recommendation, of favoring by the United Stales Government of any agency ther al. The views and opinions of authors expressed herein do not necessarily slate or reflect those of the United States Government or any agency thereol.

\title{
STABILITY OF ELONGATED CROSS-SECTION TOKAMAKS TO AXISYMMETRIC EVEN POLOIDAL MODE NUMBER DEFORMATIONS
}

\author{
R. Weiner \\ PPPL- -2626 \\ Max-Planck-Institut für Plasmaphysik \\ Garching, Germany \\ and \\ S. C. Jardin and N. Pomphrey \\ Princeton Plasma Physics Laboratory \\ P.O. Box 451, Princeton, New Jersey 08543

\begin{abstract}
A recent paper by Nakayama, Sato and Matsuoka ${ }^{1}$ suggests that elliptical cross section tokamaks with aspect ratio $R / a=3.2$ and with elongation $\kappa=2.6$ are unstable to a spliting ( $m=2, n=0$ ) instability foi plasma $\beta>5 \%$, and that $\kappa \geq 4.0$ plasmas are unstable to spliting for $\beta \geq 1 \%$. We have tried to reproduce these results using the MHD evolution code TSC, ${ }^{2}$ but find these configurations to be stable, not even near a stability boundary. Even a $x=3.7$ plasma with $\beta=23.0 \%$ is stable to the splitting mode. However, the addition of pinching coils at the waist will cause the plasma to split if the current in these coils exceeds a critical value $I_{\mathrm{c}}$ which decreases with increasing $\beta$.
\end{abstract}




\section{INTRODUCTION}

A recent paper ${ }^{1}$ presents numerical simulation results which seem to indicate that when the plasma beta in an elliptical cross-section tokamak exceeds a critical value, it becomes unstable to an ideal pressure-driven instability, which causes the ellipse to split into nwo separate pieces. This result, if true, would appear to contradict previous analytical results ${ }^{3-5}$ which say that elliptical cross-section plasmas of all elongations are stable to all even mode number axisymmetric deformations. It would also seemingly contradict results we have obtained over the last several years while performing numerous simulations of the axisymmetric evolution and stability of noncircular cross-section tokamal plasmas using the MHD simulation code TSC. ${ }^{2}$ This code has been extensively verified both by performing convergence studies and comparing test problems against analytic solutions, and by detailed comparison of the simulation results with data from several large experiments including PBX, PBX-M, TFTR, and D-III-D.

\section{SPONTANEOUS SPLITTING}

To investigate splitting modes in tokamaks, we have utilized the configuration of the proposed TCV tokamak. The vacuum vessel and the external coils of the TCV tokamak ${ }^{6}$ are modelled by single grid conductors as illustrated in the figures and listed in Table I. Additional divertor coils and pinching coils on both sivies of the plasma have been introduced to allow the investigation of divertor plasmas and to squeeze the plasma waist in order to produce doublets and induce splitting. The locations and currents in these coils are also listed in Table I.

In order to determine if the plasma spontaneously splits, as suggested by Ref. 1, we produced configuration 1 listed in Table $I$ and shown in Fig. 1, which is a high beta, high elongation reference equilibrium for TCV. ${ }^{7}$ This plasma has $I_{p}=1.2 \mathrm{MA}, \beta=23.6 \%$, and an elongation $\kappa=3.7$. For the initial equilibrium we take the pressure and toroidal field profiles to be of the form $p(\bar{\psi})=p_{0} \bar{\psi}^{\alpha}$ and $g^{2}(\tilde{\psi})=g_{0}^{2}-g_{1} \bar{\psi}^{\alpha}$, where $\bar{\psi}$ is the normalized poloidal flux and $\alpha_{p}=1.2, \alpha_{g}=0.3$. This yields a poloidal beta of $\beta_{p} \cong 1$ and an internal inductance of $l_{i} / 2=0.16$. The TSC code evolves the equilibrium into a resistive steady state. ${ }^{2}$ During the evolution the plasma density was kept at 10 cimes the Murakami density limit so as to shorten the skin time, allowing steady state to be obtained in a reasonable time. We maintained the $\beta$ of this configuration at 
$B=23.6$ by adding an energy source to force the pressure to keep its analytic profile, and evolved the MHD-Maxwell and transport equations for over two seconds in real time (several skin times), with no signs of splitting. The only feedback systems present in this calculation were a"perfect" OH system, which supplies a toroidal electric field to the boundary as needed to keep the plasma current constant, and a simple radial feedback system which adjusted the current in coils 7 and 8 to keep the outermost flux surface centered.

We conclude that a tokamak plasma of this clongation will not spontaneously split, even at large beta values well above the ballooning mode stability limit.

\section{FORCED SF LITTING USING PINCHING COILS}

In order to study forced splitring of an elongared diverted tokamak, we have introduced a set of "pinching" coils at the waist of the TCV configuration, and have made a study of the critical current in these coils needed to deform the plasma into either a stable doublet configuration with two magnetic axes, or to split it into two droplets. The configuration we use in the remainder of the studies is similar to that shown in Fig. 2. This has $I_{p}=1.2 \mathrm{MA}, \beta=11 \%$, $\kappa=3.0$. For this case we used $\alpha_{p}=1.2$ and $\alpha_{3}=1.24$, which results in a poloidal beta of $\beta_{p} \cong 0.5$ and an internal inductance of $l_{i} / 2=0.2$. The placement of the splitting and divertor coils is also illustrated is Fig 2. [It is listed as configuration 2 in Table 1.]

To demonstrate splitting in configuration 2, we ramped the current in the pushing coils 10 and 11 from 0 to $-200 \mathrm{kA}$ in $20 \mathrm{~ms}$. The other coil currents were held constant except for coils 7 and 8 , which are part of the radial control feedback system, and had their currents adjusted in time to keep the outermost flux surface centered. The "perfect" $\mathrm{OH}$ system supplied a boundary toroidal electric field to keep the plasma current constant at $I_{p}=1.2 \mathrm{MA}$. The time history of these currents is shown in Fig. 3.

The time history of the $Z$-position of the magnetic axis is shown in Fig. 4. At $t=19 \mathrm{~ms}$, just about the time the pushing coils reach full power, the plasma transforms into a doublet configuration. This doublet configuration persists, with the separation between the two axes increasing slowly in time, until $t=70 \mathrm{~ms}$, at which ime the separation increases more rapidly until the doublet splits into two droplets at $t=72.7 \mathrm{~ms}$. Three snapshots of the flux surfaces during this 
evolution are shown in Fig. 5, and in Fig. 6 we show a summary plot illustrating a superposition of the $99 \%$ flux surface locations during the evolution.

Next, we repeated the identical case as just described (configuration 2), but ramped the pushing coil currents only to $-175 \mathrm{kA}$ instead of $-200 \mathrm{kA}$ and held them at this value. The $Z$-position of the magnetic axis is shown in Fig. 7 . It is seen that a stable doublet configuration is formed, with each magnetic axis located at $Z_{\text {nas }}= \pm 0.145 \mathrm{~m}$. This configuration remained stationary until the calculation ended at $t=0.8 \mathrm{sec}$, longer than all relevant time scales. The magnetic surfaces of the stable doublet configuration at $t=0.8 \mathrm{sec}$ are shown in Fig. 8. The TSC simulation that produced this result used a computational grid with cell size $\Delta X=\Delta Z=0.0125 \mathrm{~m}$. The convergence of $Z_{\text {mag }}$ as the grid size is varied is shown as the indented plot in Fig. 7. Extrapolation to zero grid size yields $Z_{\text {mas }}= \pm 0.130 \mathrm{~m}$.

To get the plasma to split into droplets for the $-175 \mathrm{kA}$ configuration, we repeared this run, but began increasing the plasma $\beta$ by increasing the pressure starting at $t=0.3 \mathrm{sec}$. As shown in Fig. 9, the increased $\beta$ causes the plasma to split at $t=0.43, \beta=13 \%$. Another extreme case, shown after evolving for $1.5 \mathrm{sec}$ in Fig. 10, has $\beta=25.7 \%$ and a pushing coil current of $-100 \mathrm{kA}$. This is again stable, being stationary on all time scales. We have also repeated a simulation with a more peaked pressure profile $\left(\alpha_{p}=2 ; I_{\text {pinch }}=75 \mathrm{kA}\right)$ and have obtained essentially identical results. Thus, we conclude that the effect of a specific profile shape plays a minor role for stability.

\section{SUMMARY AND DISCUSSION}

In Fig. 11, we show a summary of the runs described in the text, and some additional cases not described. For each $\beta$ value considered, up to $36 \%$, there is a critical value of current in the pushing coils that causes the plasma to split. We have never seen a tokamak split for any elongation or any beta, unless pinching coils with nonzero current are placed at the waist to force the splitting. The current in these coils necessary to induce spliting does decrease with increasing beta. When no pinching coil currents were applied, we were able to get a stable single magnetic axis equilibrium even with $\kappa=7$ and $\beta_{t}=70 \%$.

Below the critical values for spliting, we found a broad range of stable single maglietic axis configurations. and doublets with two magnetic axes, even at high pressure. Figure 11 also indicates the critical limits where the plasma bifurcates 
from a singlet to a doublet configuration. Our explanation for bifurcation is that the surrounding coils must be strong enough to produce a saddle point at the original single magnetic axis position. This leads to a reconnection of the innermost fiux surfaces and causes the magnetic axis to move off the midplane. After bifurcation the plasma either attains a stable configuration or it splits, depending on the pressure and the pinching coil currents. We conclude that the splitting instabilities are of no concem for presently envisaged advanced tokamaks.

\section{ACKNOWLEDGMENTS}

We thank F. B. Marcus for providing us with a TCV data set for the TSC code and for stimulaing discussions. This work is supported by U.S. Department of Energy Contract No. DE-AC02-76CHO3073. 


\section{References}

'Y. Nakayama, T. Sato, K. Matsuoka, Phys. Fluids 31, 630 (1988).

${ }^{2}$ S.C. Jardin, N. Pomphrey, J. DeLucia, J. Cori.jut. Phys. 66, 481 (1986).

${ }^{3}$ G. Laval, R. Pellat, J.S. Soule Phys. Fluids 17, 835 (1974).

${ }^{4}$ R.L. Dewar, R.C. Grimm, J.L. Johnson, E.A. Frieman, J.M. Greene, P.H. Rutherford, Phys. Fluids 17, 930 (1974).

${ }^{5}$ P.H. Rutherford, Princeton Plasma Physics Laboratory Repor PPPL-976 (1973).

${ }^{6}$ F.B. Marcus, S.C. Jardin, F. Hofmann, Phys. Rev. Lett. 55, 2289 (1985).

'F.B. Marcus, private communication.

${ }^{8}$ S.C. Jardin, et al., Nucl. Fusion 27, 569 (1987). 


\section{Table}

TABLE I. Coil Locations and Currents used in Simulations.

\begin{tabular}{ccrrr}
\hline \hline & \multicolumn{2}{c}{ Position } & \multicolumn{2}{c}{ Configuration } \\
Coil & $R(\mathrm{~m})$ & $Z(\mathrm{~m})$ & $I_{1}^{0}(\mathrm{kA})$ & $I_{2}^{0}(\mathrm{kA})$ \\
\hline 1 & 0.475 & \pm 0.100 & -322 & -277 \\
2 & 0.475 & \pm 0.300 & -216 & -215 \\
3 & 0.475 & \pm 0.500 & -313 & -280 \\
4 & 0.475 & \pm 0.700 & -215 & -183 \\
5 & 1.300 & \pm 0.750 & -29 & -40 \\
6 & 1.300 & \pm 0.600 & -153 & -164 \\
7 & 1.300 & \pm 0.300 & -66 & -66 \\
8 & 1.300 & \pm 0.150 & -212 & -167 \\
$9^{*}$ & 0.850 & \pm 0.875 & 0 & 100 \\
$10^{*}$ & 0.600 & 0.000 & 0 & $0 \sim-200$ \\
$11^{*}$ & 1.150 & 0.000 & 0 & $0 \sim-200$ \\
\hline \hline
\end{tabular}

*These coils are not present in the acrual TCV experiment. 


\section{Figures}

FIG. 1. Flux surfaces of $\beta=23.6 \%, x=3.7$ equilibrium which is stable to splitting.

FIG. 2. Flux surfaces of $\beta=11 \%, \kappa=3.0$ diverted equilibrium showing diveror and pinching coils.

FIG. 3. Time history of coil currents used to force splitting.

FIG. 4. Time history of magnetic axis $Z$-coordinate. Doublet forms at $t=19$ ins and plasma splits at $t=70 \mathrm{~ms}$.

FIG. 5. Magnetic surfaces at the three times marked in Fig. 4 showing tokamak splitting.

FIG. 6. Summary of $99 \%$ flux surface location for (a) $0<t<0.070 \mathrm{sec}$ and (b) $0.070<t<0.072$ sec.

FIG. 7. Magnetic axis 2 -position vs time for stable doublet with $I_{\text {pinch }}=$ $-175 \mathrm{kA}$. Also, convergence of $Z_{\text {mes }}$ with respect to computational grid size.

FIG. 8. Magnetic flux surfaces for stable doublet at $t=0.8 \mathrm{sec}$ in Fig. 7.

FIG. 9. Time history of plasma $\beta$ and magnetic axis $Z$-position, Plasma split at $t=0.43, \beta=13 \%$.

FIG. 10. Flux surfaces of stable $\beta=25.7 \%$ case with pushing coil current of $-100 \mathrm{kA}$.

FIG. 11. Critical current in pushing coils as a function of plasma beta. 
\#89T0023

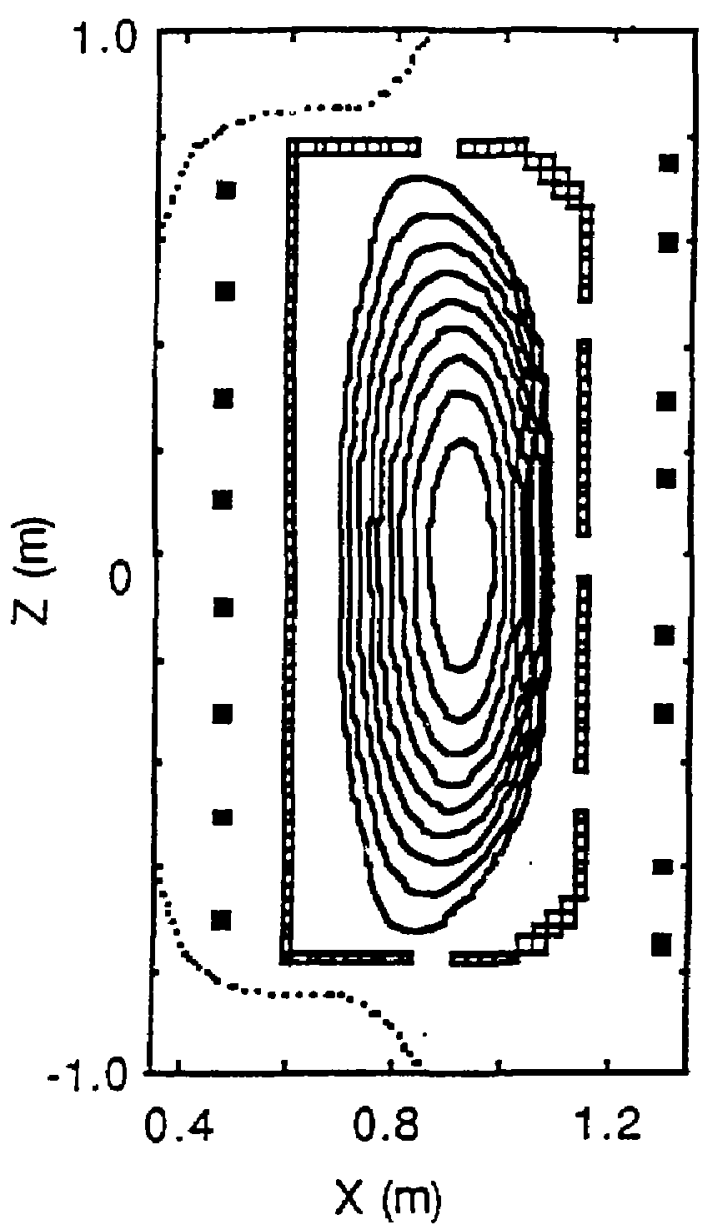

EIG. 1 


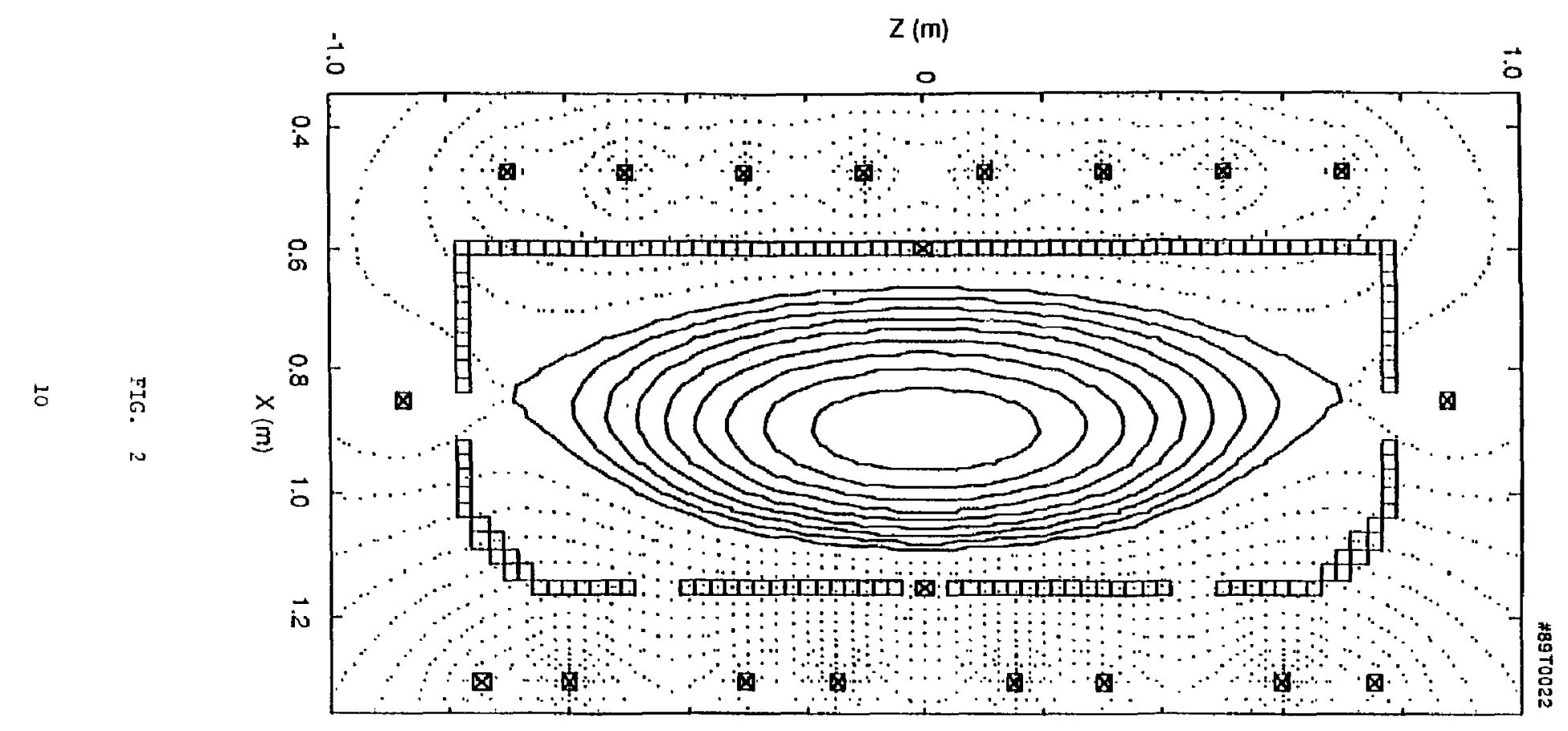


$\#$ BQT0024

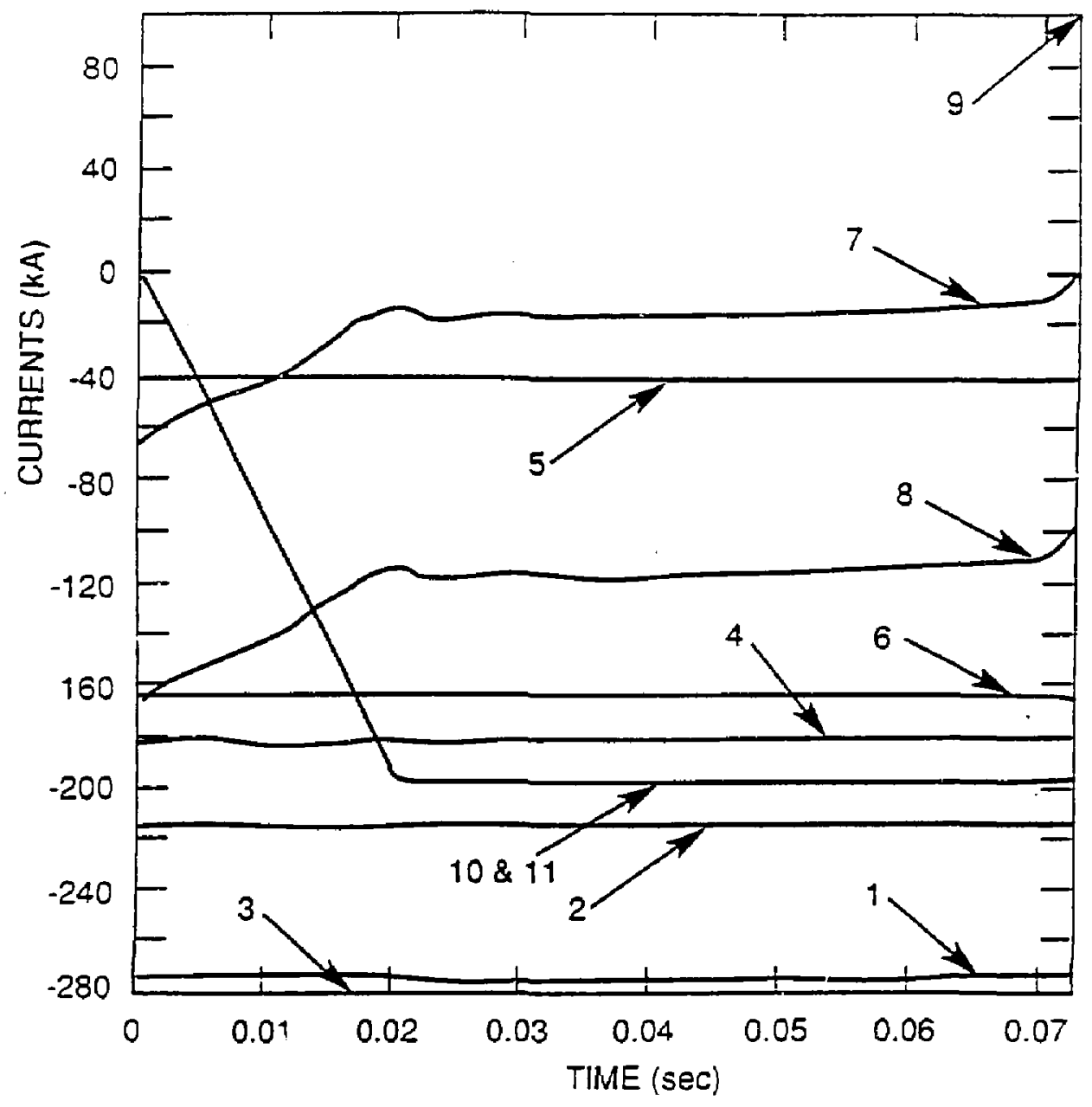

FIG. 3 


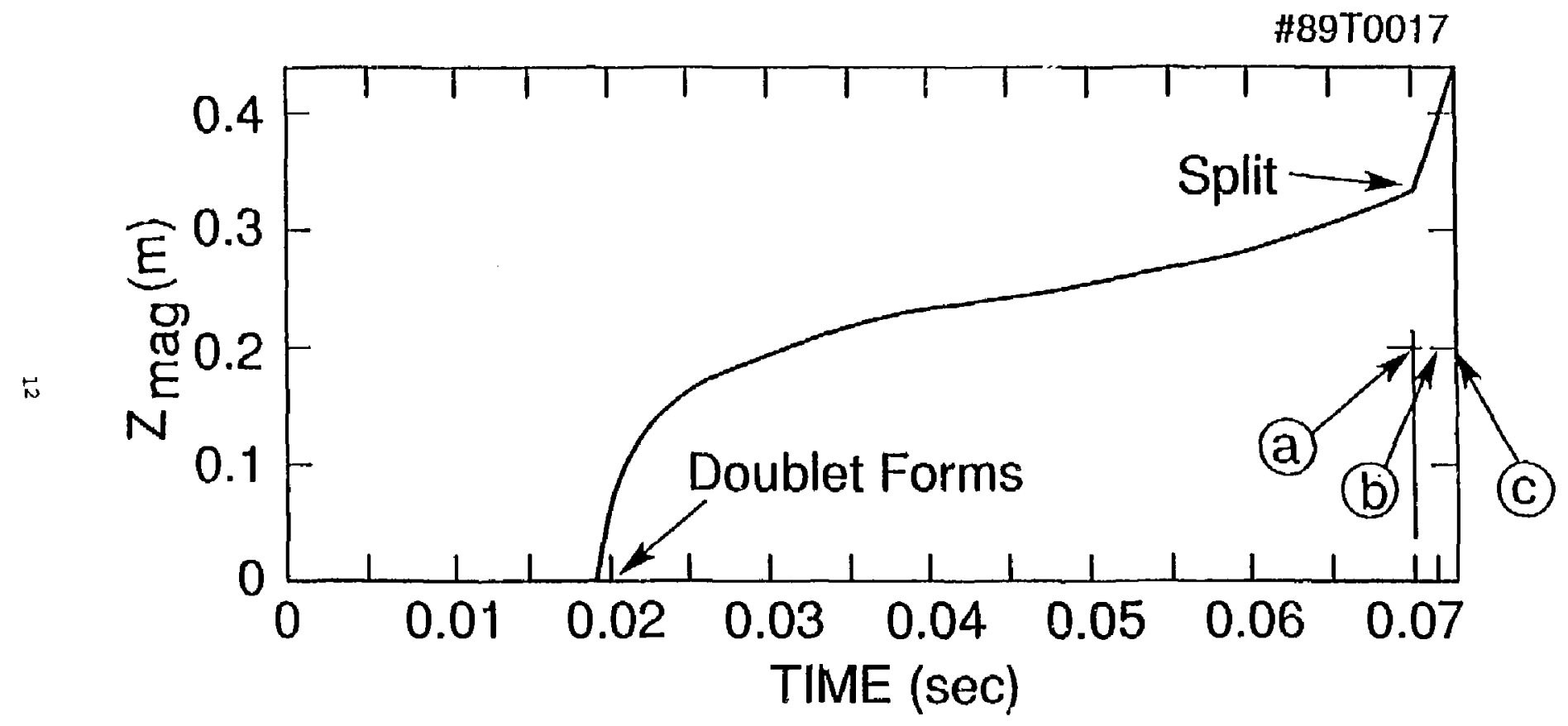

FIC. 4 

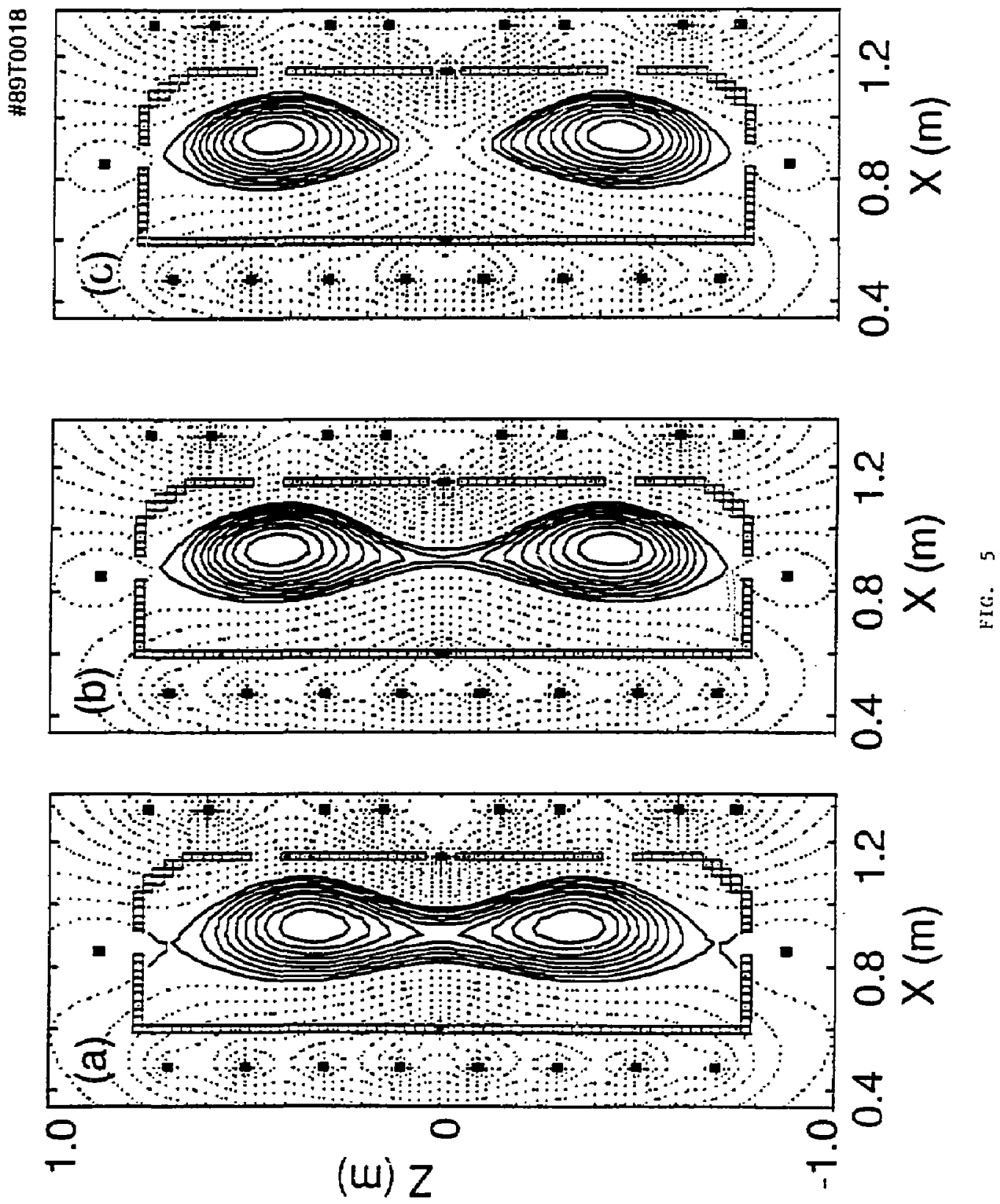


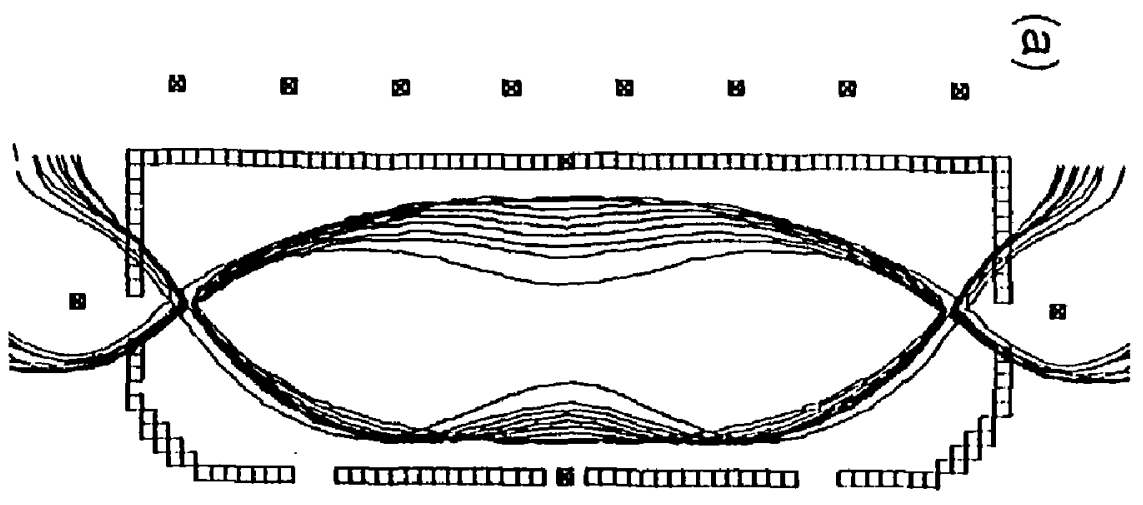

$\Delta \quad * \quad * \quad * \quad \widehat{\sigma}$

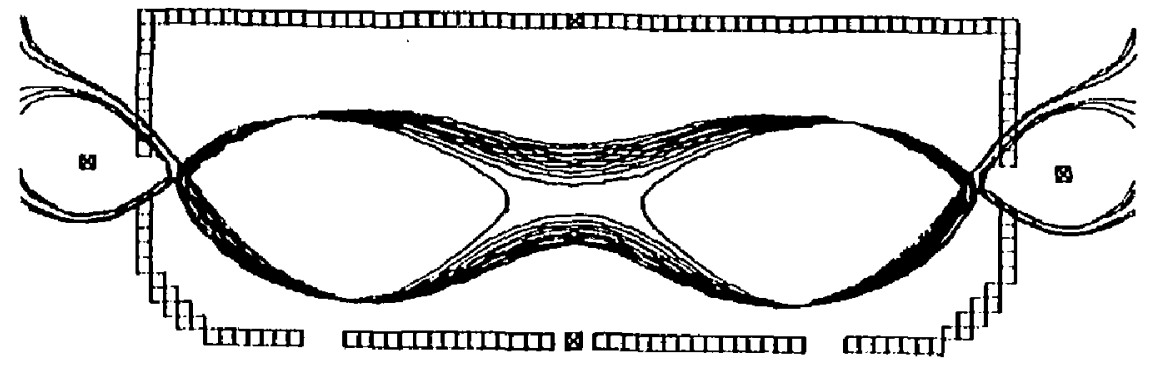

- $\mathbf{4}$

(2)

1 $\mathbf{0}$

$\infty \quad \infty$ 


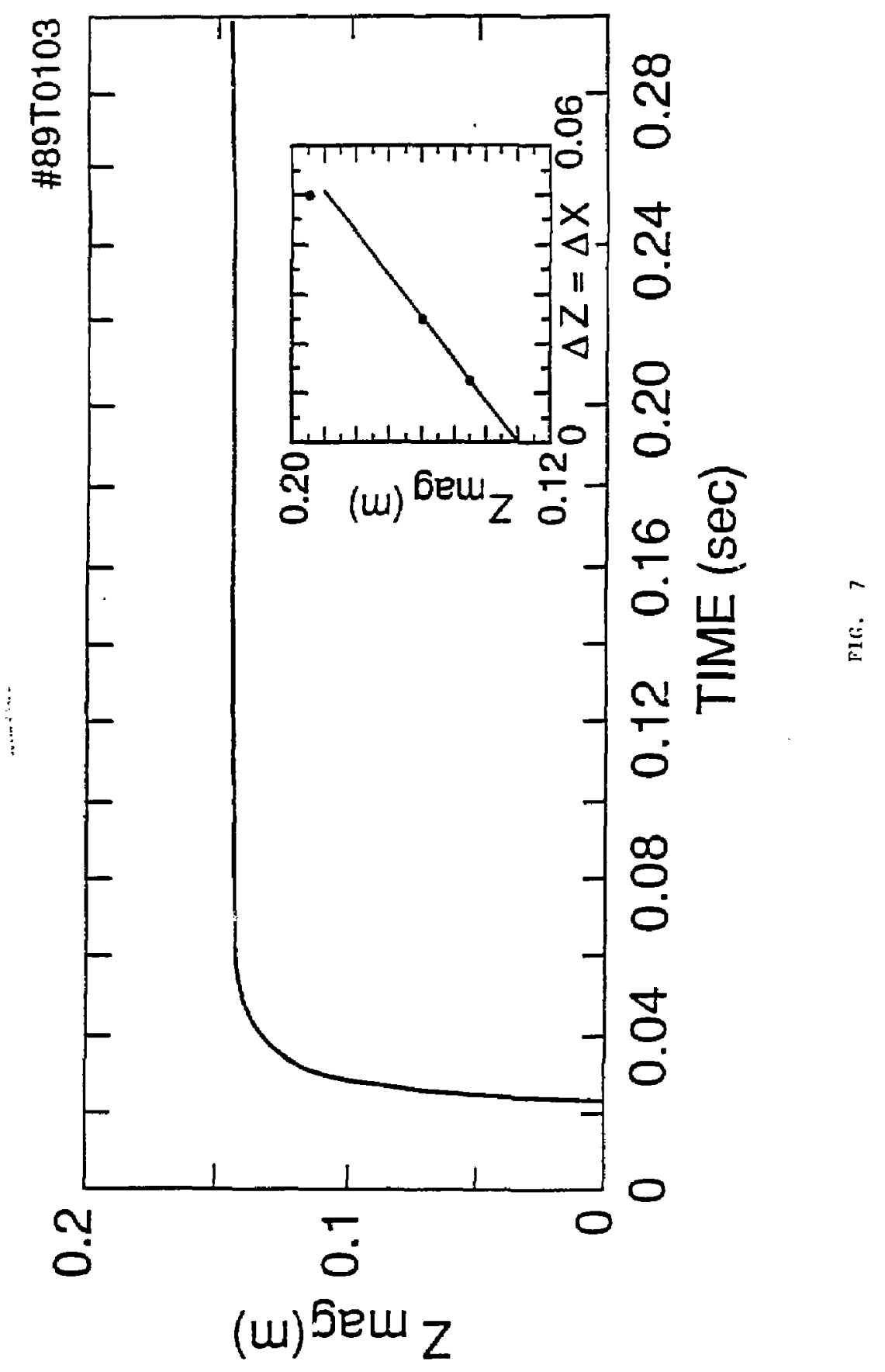


\#89T0025

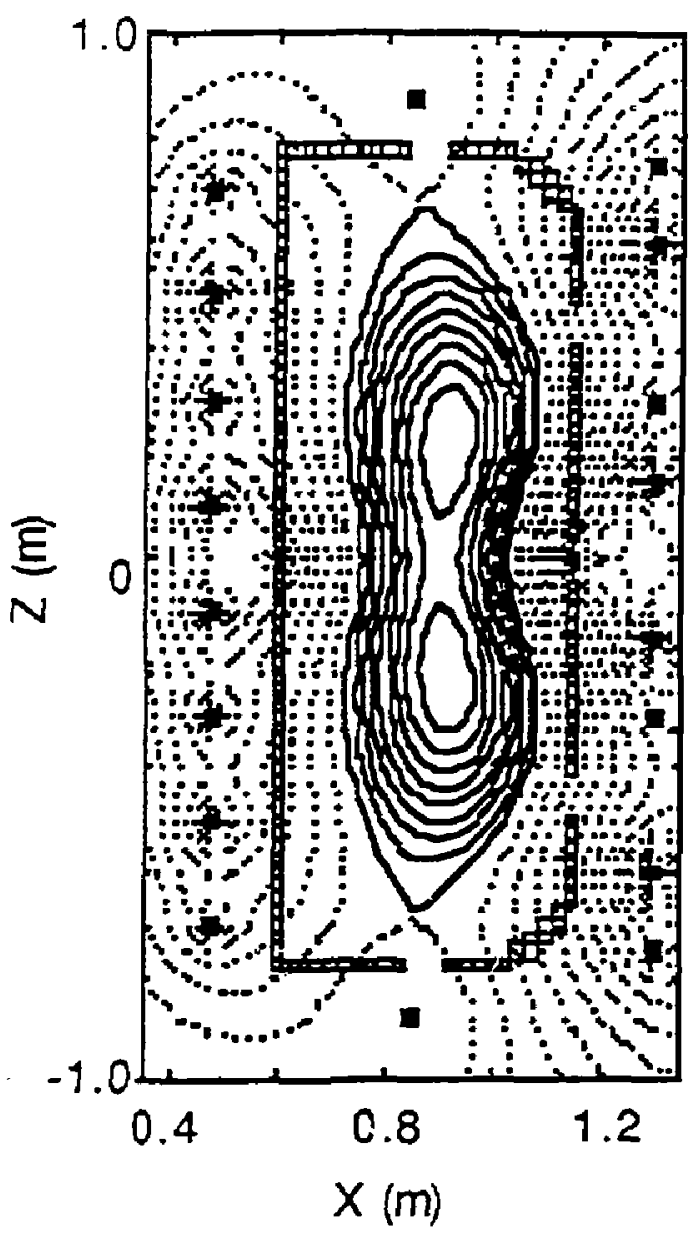

FIง 8 
\#89T0021
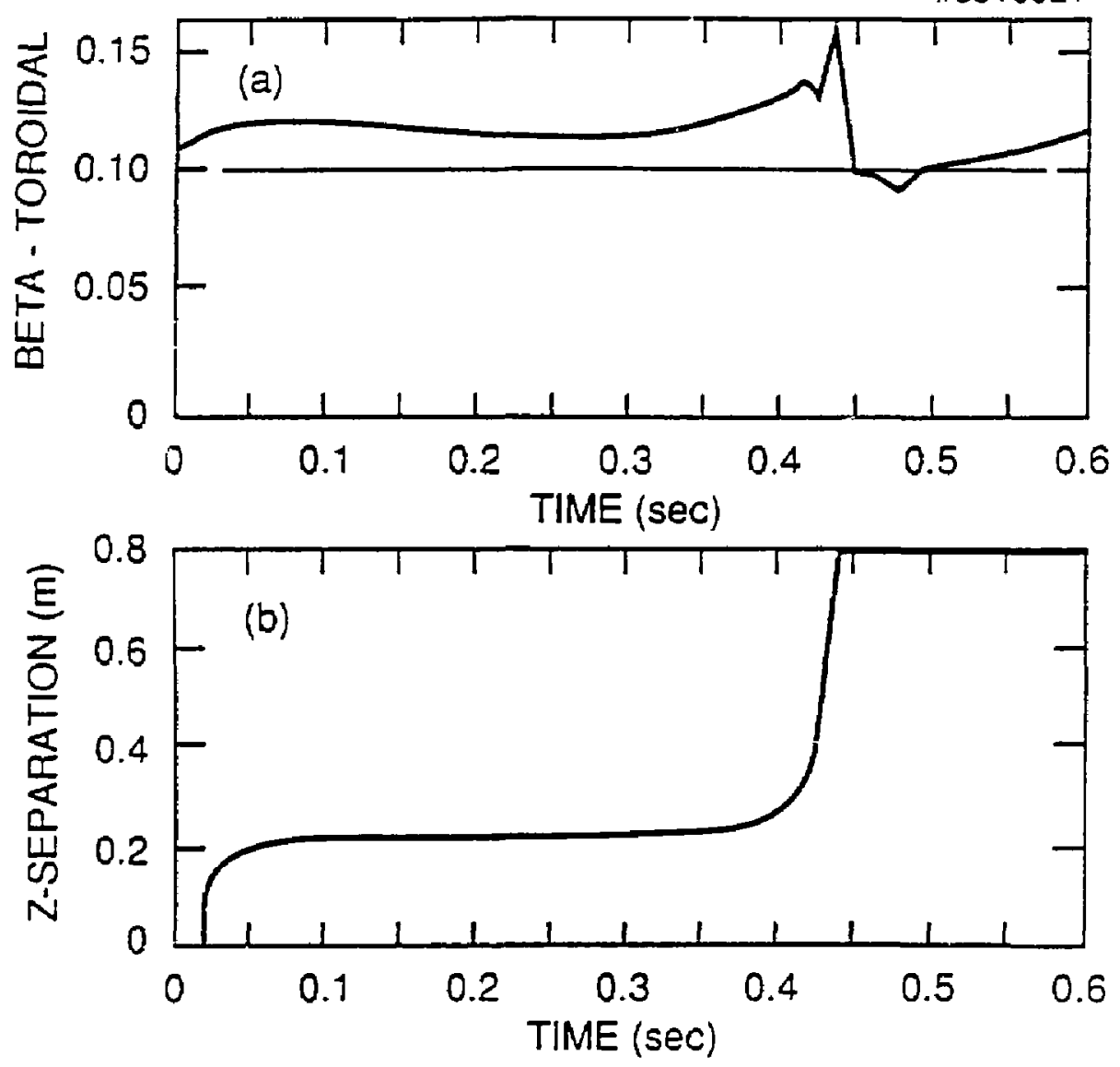

FIC. 9 


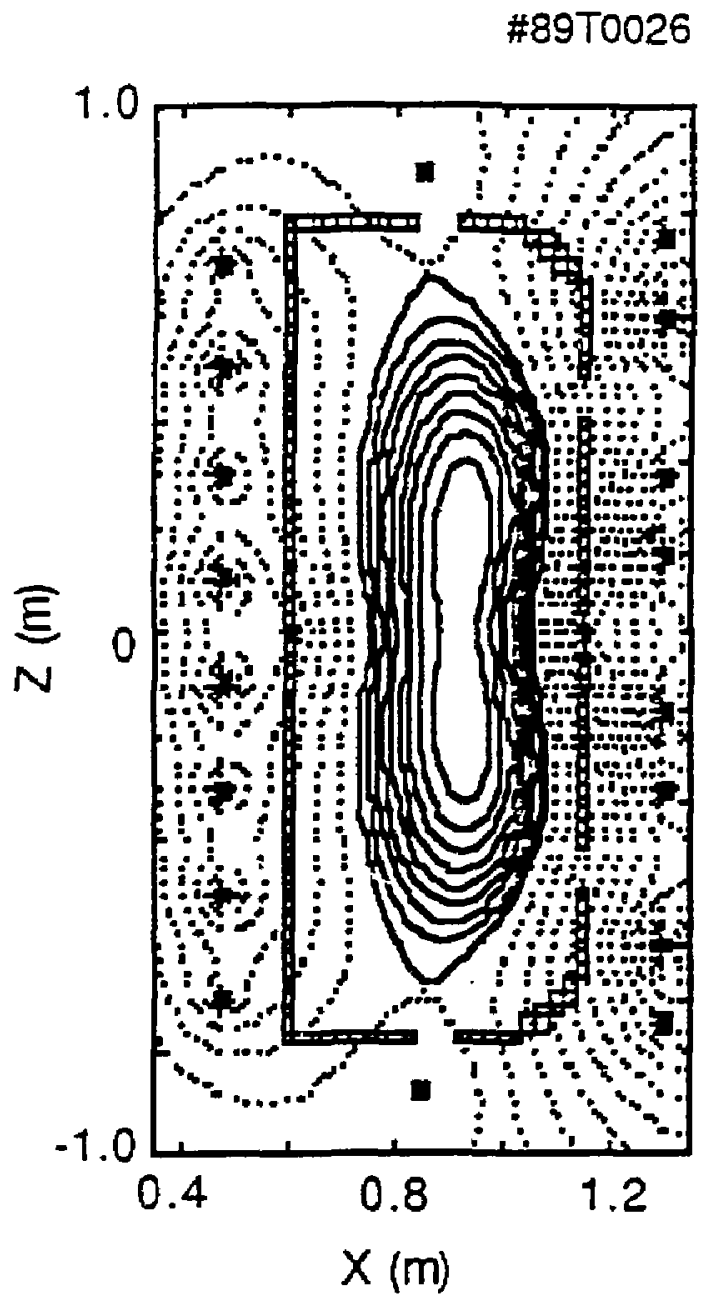

FIG. 10 


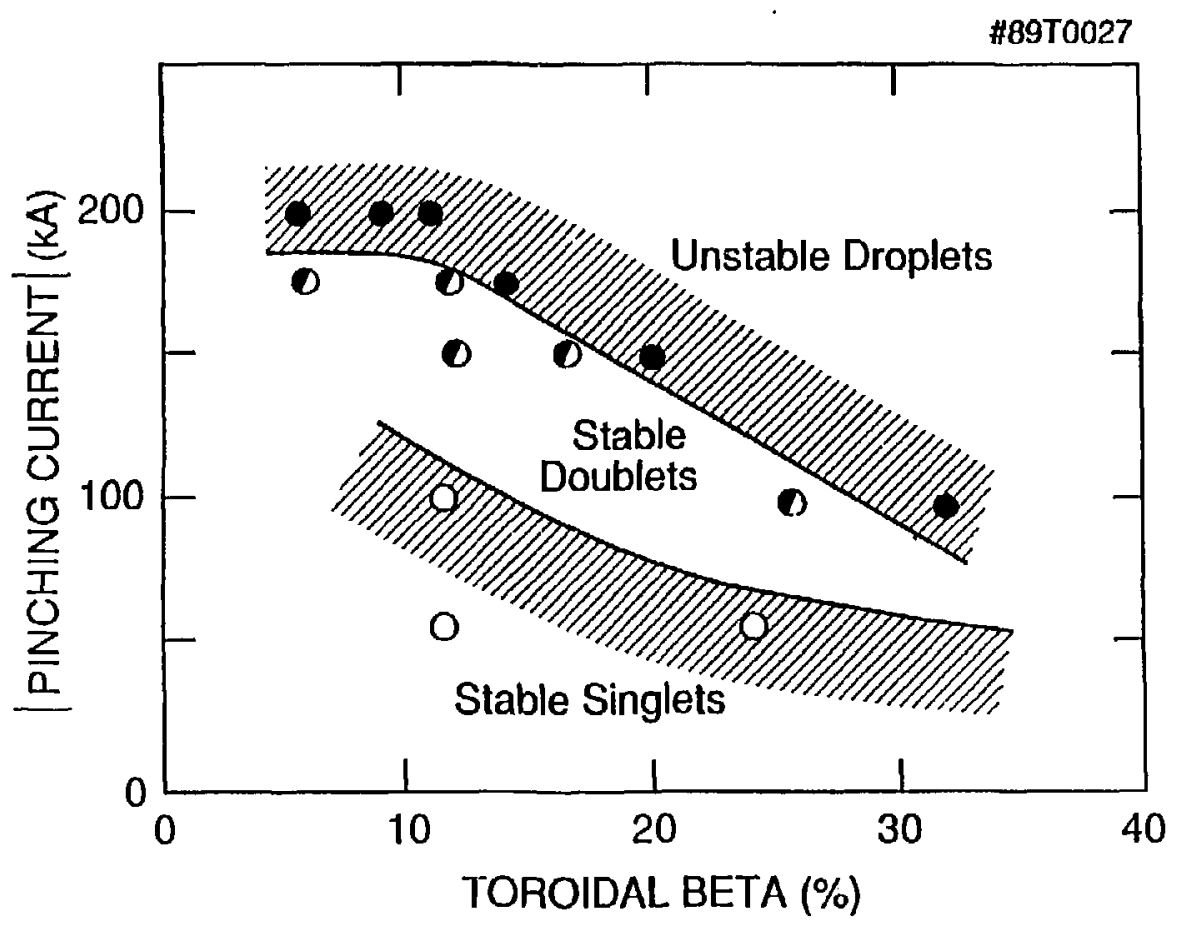

FIs. 11 
Or. Frank J. Peotoni, univ of wollongong, Australla Prof. M.H. Brennan, Uniy Sydney, AusTRaliA PIasag Researen Lab., Nustralian Nat. Univ., AUSTRALdA Prot, 1,R, Jones, Flinders Univ., Austrabia Prof. F. Cap, Inst Theo Phys, Austain Prot. M. Heindler, Instut fur Theoratlsche Physik, AUSTRIA M. Goossens, Astronatiseh Instituut, BeLGIUM Ecole Royte mllitaira, Leb Phys PIasmes, BELGILy comassion-Eurogean, Og-XII Fusion Prog, Belgium Prof. R. Bowcique, Rljksuniyorsitelt Gant. Belgluy Dr. P.H. Sakanake, Intetiquto Fisice, BRazil Instituto De Pasquisus Espaciasi-INPE, BRAZ1L Documents Office, Atomic Energy of Conede biaited, Cukaoh Or. M.P. Bechynski, wa Technologies, Ine., Cewaph Dr. H.H. Skersgard, University of Saskatehewen, cawan Dr. H. Barnard, University of British Columit, camon Prot. t. Toichmann, Uniy. of montrasl, cakwan Prot. S.R. Srconivasen, University of Celgary, Cawas Prot. Tudor w. Johnston, thes-Enargie, cuwaon Or. Bolton, Contre canedien de fution angiatique, chroa Dr. C.R. tams, Unit. of Mlourte, Cuwd Qr. Poter Lukee, Komenaketo Univ, CZEOESI OVAKIA The Librarien, Culne Leboratory, EMGLNO The Librerian, Ruthertord Appleton Laboratory. EkGLAND Hrs. S.A. Hutchinson, JET Library, EkeLNO

C. Mouttet, Lab. Lo Physique dos Milioux Ionises, FRACE J. Racht, CEh/CAOARuate - Bat 506, FRANCE

Ms. C. Rinni, Librarien, Univ. of loannina, GeECE

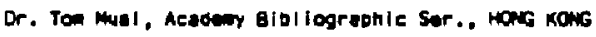

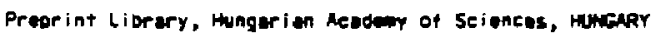
Dr. B. Des Gupta. Sathe Inst of Nucl, Phys., Incila Or. P. Xar, Instituto for Plesen Resourch, INGIA Dr. Philid Rosunau, Israsi inst, of Tuch, ISAMEL Librarian, Int'I Ctr Theo Phys, ITAcY Prot. G. Aostagni, Istituto Gas Ionizzati Del CHR, ITALY Miss Cielia on Paic, Assoc ElRatom-EMEA, ITALY Dr. G. Grosso, Istituto di fisica del Piasad, ITALY Dr. H. romato, Toshibe Ras a Der, JAPAN
Prof. I. Kawakent, Atomic Energy Res. Institute, JAPAN Prot. Kyoji Nishikama, Uniy at Hiroshima, JAPAN Diractor. Dept. Large TOkamak Ras. JAERI, JAPAH Prot, Satoshi Itoh, Kyushu University, JAPAN Regaareh into Canter, Nagoya Univarsity. JAPAN Prof. S. Tanaka, Kyoto Univarsity, JAPAN Library, Kyoto University, JAPAN Prot. Nobuyuki Inous, Univarsity of Tokyo, JAPAN 5. Mori, JAERT, JAPAN

H. Jeong, Librarion, Kores Advenced Energy Res Inst, KOREA Prof. D.1. Choi, The Kores adv, Inst of 5ci \& roek, KOREA Prof. B.5. Liley, University of Haikato, WEH ZEALAND Institute of Plasma Physies, PEOPLE'S REPJgl IC OF CHINA Librarian. Instituta of Phys., PEOPLE'S REPUBLIC OF CHINA Librory. Tsing Hu Univarsity, PEOPLE'S REPUBLIC OF CHINA 2. Li, Southwast Inst. Physics. PECPLE'S REPJeIIC OF CHIM Prot, J,A.C. Cabrat, Inst Subarior Tecnico, POATUGal Dr. Octavian Patrus, AL 1 CUZA University, ROMANIA Or. Jer de Villiars, Fusion Srudies, AEC, SO AFRICa Prof. MaA. Hallberg, University' of Natol, SO AFRICA C.J.E.M.A.T., Fusion Div. Libracy, SPAly Dr. Lemnart Stentlo, University af UEEA, SWEGEH Library, Royal institute of Teen, SHEDEN

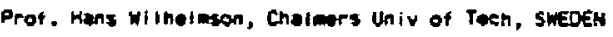
Cantre Phys des PIasans, Ecole Polytech Fed, SwITZERL Mro Gibliotheak, Foe-Inst Voor Plasmo-fysicd, THE METHERLANOS Metin Durgut, Middle East Technical University, TURXEY Dr. D.D. Ryutov, Sibari an Aead Sci, USSR Dr. G.A. Eliseer, Kurchatov Institute, USSA Dr. V.A. Gluknikh, Inst Electrophys icar Apdaratus, USSR Prof. O,S. Padichanko, Inst. of Phys. I Tech. USSR Dr. L.M. Kowrizhnykh, institute of Gen. Physics, USSR Mucleor Ras. Estoblisheunt, Julich Ltd., W. GERAMNY Bibliothak, Inst. Fur Plasmeforschung, W. Gepauny Or. K. Senindlar, Ruhr-Universitat Bochum, W. GEPanANY

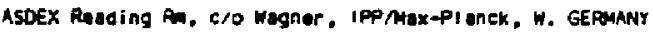
Liorarian, Maxtlanck Institut, W. GEPanky Prot, R.K. Jamev, Inst or Phys, YugosLAvia 